\title{
Analisis Pengaruh PDRB terhadap Kinerja Perkonomian Kota Surabaya Tahun 2015-2019
}

\author{
Yandi Suprapto $^{* 1}$, Eddy Oktarianto ${ }^{2}$, Junita $^{3}$, Andryanto ${ }^{4}$, Rudiyanto ${ }^{5}$, Jovianto ${ }^{6}$ \\ 1,2,3,4,5,6 Manajemen, Fakultas Ekonomi, Universitas Internasional Batam, Indonesia \\ Email: 1'yandi.suprapto@uib.edu, 2041120.eddy@uib.edu, ${ }^{3} 2041122 . j u n i t a @ u i b . e d u$,

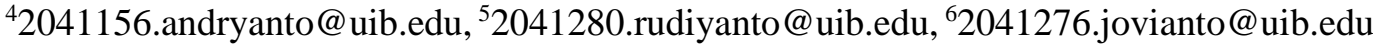

\begin{abstract}
Abstrak
Tujuan dari penelitian ini adalah untuk mendeskripsikan hasil analisis PDRB Kota Surabaya atas dasar harga konstan, laju indeks implisit PDRB, sebaran PDRB Kota Surabaya dari tahun 2015 sampai dengan tahun 2019. Penelitian ini menggunakan metode deskriptif kualitatif yang bertujuan untuk mengidentifikasi dan menjelaskan suatu masalah dari hasil analisis. Hasil dari penelitian ini adalah setiap tahun nilai PDRB Kota Surabaya terus meningkat sebagai akibat dari turunnya harga produsen setiap tahunnya. Kesimpulan dari penelitian ini adalah pertumbuhan penduduk berdampak negatif karena dapat meningkatkan tingkat kemiskinan, kekurangan pangan, pemerintah kesulitan menyediakan fasilitas untuk kebutuhan masyarakat dan ketidakseimbangan kebutuhan akan lapangan kerja.
\end{abstract}

Kata kunci: Ekonomi, PDRB, Pertumbuhan, Surabaya

\begin{abstract}
The purpose of this study is to describe the results of the Surabaya City PDRB analysis on the basis of constant prices, the rate of the PDRB implicit index, the distribution of the Surabaya City PDRB from 2015 to 2019. This study uses a qualitative descriptive method which aims to identify and explain a problem from the results of the analysis. The results of this study are that every year the value of the PDRB of the City of Surabaya continues to increase as a result of the decline in producer prices every year. The conclusion of this study is that population growth has a negative impact because it can increase the level of poverty, lack of food, the government has difficulty providing facilities for community needs and the imbalance in the need for employment.
\end{abstract}

Keywords: Economy, Growth, PDRB, Surabaya.

\section{PENDAHULUAN}

Pembangunan daerah merupakan sebuah bagian yang integral dari pembangunan bangsa dan negara (Ratnadila, 2018). Pemberian otonomi daerah dalam UU diatur dalam UU No. 32 Tahun 2004 memberikan kesempatan kepada pemerintah daerah untuk menganggarkan sendiri pendapatan dan belanja daerahnya sesuai dengan potensi dan kebutuhan daerah (Horota et al., 2017). Pertumbuhan ekonomi daerah dapat ditentukan dengan menggunakan Produk Domestic Regional Bruto (PDRB) sebagai indikatornya (Horota et al., 2017). PDRB adalah sebuat metode penjumlahan nilai tambah produk yang dihasilkan dari semua aktivitas ekonomi di seluruh wilayah dalam kurun waktu tertentu. PDRB dapat diperkirakan dengan memakai 2 pendekatan diantaranya harga konstan dan harga berlaku (Dama, 2016). PDRB ADHB adalah dasar dari harga yang berlaku, ini merupakan sebuah nilai tambah dari produk yang diperkirakan dengan memakai nilai yang berlaku pada tahun yang bersangkutan (Mudji \& Taripar, 2018). Sedangkan PDRB ADHK yaitu dasar dari harga konstan, PDRB ini diperkirakan dengan memakai nilai pada tahun yang sudah ditentukan sebagai tahun acuan (Perdana et al., 2020).

Kota Surabaya dijuluki sebagai kota pahlawan. Kota terbesar kedua di Indonesia merupakan kota Surabaya dan kota Surabaya dikenal juga dengan pusat industri, bisnis, perdagangan, dan pendididkan dikawasan pulau jawa bagian timur dan sekitarnya (Sutrisno, 2015). Kota Surabaya mempunyai sekitar 
3.15 juta jiwa ditahun 2019 dan terjadi inflasi penduduk pada kota Surabaya saat ini sebesar $2.34 \%$ dan pertumbuhan penduduknya mencapai $2.07 \%$ dan kepadatan penduduk pada kota Surabaya yaitu mencapai $9.497 / \mathrm{km}^{2}$.

Penelitian ini bertujuan untuk mengukur kinerja dari keuangan pada suatu daerah dan menjadikan salah satu kajian yang menarik untuk dianalisis lebih dalam dan alasannya penelitian ini juga menghasilkan data yang penting bagi daerah yang sudah dianalisis sehingga kedepannya data-data ini berguna untuk penghitungan kinerja keuangan pada daerah tersebut dan penelitian ini juga mengidentifikasi dan analisis pertumbuhan daerah pada Surabaya dalam hal statistik pendapatan serta pembiayaan daerah.

\section{METODE PENELITIAN}

Dalam pelaksanaan penelitian, peneliti menggunakan data primer dan data sekunder. Data primer adalah sejenis data yang didapatkan oleh seorang peneliti secara langsung dari sumber utama (Tineges, 2021), dimana data-data yang didapatkan dari BPS (Badan Pusat Statistik) Kota Surabaya yang akan digunakan untuk menganalisis PDRB Kota Surabaya dari tahun 2015 sampai 2019. Sedangkan, data sekunder merupakan data yang didapat dari sumber lain (Tineges, 2021), dimana data-data diperoleh berbagai artikel maupun jurnal mengenai analisis PDRB, laju indeks implisit PDRB dan distribusi Surabaya yang berasal dari google scholar.

Penelitian ini memakai metode deskriptif kualitatif dengan tujuan untuk mengetahui dan menjelaskan suatu masalah dari hasil analisis (Widyananda, 2021). Dengan metode ini, peneliti akan mendeskripsikan data mengenai PDRB Kota Surabaya dari tahun 2015 sampai 2019.

Analisis data pada penelitian yang dilakukan adalah mendeskripsikan hasil analisis PDRB, laju indeks implisit PDRB, distribusi PDRB Surabaya dari tahun 2015 sampai 2019. Adapun langkahlangkah dalam analisis data (Yuliani, 2018) diantaranya penarikan kesimpulan, data display dan reduksi data (Sugiyono, 2013). Penarikan kesimpulan merupakan sebuah usaha yang dilakukan oleh tim peneliti untuk mencari sebab akibat pengaruh PDRB terhadap kinerja perekonomian kota Surabaya tahun 20152019. Display data adalah suatu cara atau teknik penyajian data, dimana bisa dilaksanakan dalam bentuk grafik dan tabel agar bisa dengan mudah dihubungkan dan dipahami, tabel yang disajikan oleh peneliti dalam artikel penelitian berupa data-data mengenai Nilai PDRB kota Surabaya dan Laju Pertumbuhan kota Surabaya. Reduksi data adalah suatu bentuk analisis data yang memberikan pengarahan, penggolongan, serta membuang data-data yang tidak begitu diperlukan, dan melakukan pengorganisasian suatu data dengan sedemikian rupa sehingga kesimpulan akhir bisa diambil dan dilakukan diverifikasi.

\section{HASIL DAN PEMBAHASAN}

Dari data hasil analisis lima tahun $(2015,2016,2017,2018,2019)$ pada Tabel 1 yang penulis dapatkan dari BPS Kota Surabaya, penulis dapat mengambil data bahwa Nilai PDRB pada tahun 2015 mencapai angka Rp. 324.215.166,88 dalam nilai jutaan rupiah, tahun 2016 mencapai angka Rp. 343.652.595,01 dalam nilai jutaan rupiah, tahun 2017 mencapai angka Rp. 364.714.819,48 dalam nilai jutaa rupiah, tahun 2018 mencapai angka Rp. 387.303.942,07, dan pada tahun 2019 mencapai angka Rp. 410.879.306,14 dalam nilai jutaan rupiah. Dapat kita asumsikan pada tahun 2015 - 2016 mengalami peningkatan sebesar Rp. 19.437.428,13 dalam nilai jutaan rupiah, tahun 2016 - 2017 mengalami peningkatan sebesar Rp. 21.062.224,47 dalam nilai jutaan rupiah, tahun 2017 - 2018 mengalami peningkatan sebesar Rp. 22.589.122,59 dalam nilai jutaan rupiah, tahun 2018 - 2019 mengalami peningkatan Rp. 23.575.364,07 dalam nilai jutaan rupiah. Dapat penulis simpulkan bahwa setiap tahun nilai PDRB Kota Surabaya terus mengalami peningkatan akibat dari menurunnya harga produsen setiap tahunnya. Untuk mengetahui persentase penurunan harga produsen setiap tahun, penulis sajikan Tabel 2 mengenai laju indeks implisit PDRB kota Surabaya. 
Tabel 1. Tabel PDRB Kota Surabaya atas Dasar Harga Konstan Menurut Lapangan Usaha, 2015-2019 (Dalam Jutaan Rupiah)

\begin{tabular}{|c|c|c|c|c|c|}
\hline \multirow{2}{*}{ Kategori / Sektor } & \multicolumn{5}{|c|}{ Nilai PDRB Kota Surabaya (Dalam Jutaan Rupiah) } \\
\hline & 2015 & 2016 & 2017 & 2018 & 2019 \\
\hline $\begin{array}{l}\text { Pertanian, Kehutanan, dan } \\
\text { Perikanan }\end{array}$ & $546.940,3$ & $570.789,40$ & $589.909,43$ & $581.426,57$ & $576.221,53$ \\
\hline $\begin{array}{l}\text { Pertambangan dan } \\
\text { Penggalian }\end{array}$ & $19.418,14$ & $20.028,08$ & $20.544,80$ & $20.762,58$ & $20.782,09$ \\
\hline Industri Pengolahan & $\begin{array}{c}63.467 .797,3 \\
3\end{array}$ & $\begin{array}{l}66.582 .825,6 \\
2\end{array}$ & $\begin{array}{l}69.881 .287,9 \\
2\end{array}$ & $\begin{array}{c}73.322 .747,3 \\
8\end{array}$ & $\begin{array}{c}77.271 .868,8 \\
1\end{array}$ \\
\hline Pengadaan Listrik dan Gas & $1.530 .668,43$ & $1.514 .658,16$ & $1.541 .129,01$ & $1.540 .006,38$ & $1.546 .272,08$ \\
\hline $\begin{array}{c}\text { Pengadaan Air, Pengelolaan } \\
\text { Sampah, Limbah dan Daur } \\
\text { Ulang }\end{array}$ & $498.808,24$ & $528.322,41$ & $564.406,83$ & $583.121,24$ & $605.979,60$ \\
\hline Konstruksi & $\begin{array}{l}32.250 .136,1 \\
6\end{array}$ & $\begin{array}{c}33.864 .739,1 \\
0\end{array}$ & $\begin{array}{c}36.208 .179,0 \\
4\end{array}$ & $\begin{array}{c}38.480 .421,6 \\
0\end{array}$ & $\begin{array}{c}40.576 .452,6 \\
2\end{array}$ \\
\hline $\begin{array}{c}\text { Perdagangan Besar dan } \\
\text { Eceran; Reparasi Mobil dan } \\
\text { Sepeda Motor }\end{array}$ & $\begin{array}{c}92.084 .794,2 \\
0\end{array}$ & $\begin{array}{l}97.443 .597,6 \\
5\end{array}$ & $\begin{array}{c}103.301 .112 \\
79\end{array}$ & $\begin{array}{c}109.848 .223 \\
51\end{array}$ & $\begin{array}{c}116.305 .502 \\
48\end{array}$ \\
\hline $\begin{array}{l}\text { Transportasi dan } \\
\text { Pergudangan }\end{array}$ & $\begin{array}{c}15.797 .144,7 \\
2\end{array}$ & $\begin{array}{l}16.569 .183,7 \\
5\end{array}$ & $\begin{array}{c}17.707 .950,2 \\
2\end{array}$ & $\begin{array}{c}19.046 .861,5 \\
8\end{array}$ & $\begin{array}{c}20.497 .977,4 \\
3\end{array}$ \\
\hline $\begin{array}{c}\text { Penyediaan Akomodasi dan } \\
\text { Makan Minum }\end{array}$ & $\begin{array}{l}45.918 .309,1 \\
5\end{array}$ & $\begin{array}{l}49.881 .297,6 \\
9\end{array}$ & $\begin{array}{c}54.192 .882,2 \\
1\end{array}$ & $\begin{array}{c}58.411 .739,3 \\
9\end{array}$ & $\begin{array}{c}62.886 .688,7 \\
6\end{array}$ \\
\hline Informasi dan Komunikasi & 20.958 .313 & $\begin{array}{c}22.421 .127,2 \\
2\end{array}$ & $\begin{array}{c}23.974 .911,3 \\
3\end{array}$ & $\begin{array}{c}25.613 .455,8 \\
6\end{array}$ & $\begin{array}{c}27.531 .903,7 \\
1\end{array}$ \\
\hline $\begin{array}{c}\text { Jasa Keuangan dan } \\
\text { Asuransi }\end{array}$ & $\begin{array}{c}15.964 .079,1 \\
1\end{array}$ & $\begin{array}{c}17.184 .785,5 \\
2\end{array}$ & $\begin{array}{c}17.685 .808,0 \\
4\end{array}$ & $\begin{array}{c}18.541 .116,1 \\
4\end{array}$ & $\begin{array}{c}19.187 .832,5 \\
4\end{array}$ \\
\hline Real Estate & $8.683 .388,83$ & $9.145 .630,78$ & $9.610 .228,83$ & $\begin{array}{c}10.165 .858,6 \\
7\end{array}$ & $\begin{array}{c}10.784 .959,4 \\
6\end{array}$ \\
\hline Jasa Perusahaan & $7.388 .567,18$ & $7.761 .412,08$ & $8.278 .199,91$ & $8.867 .969,79$ & $9.474 .538,92$ \\
\hline $\begin{array}{c}\text { Administrasi Pemerintahan, } \\
\text { Pertahanan dan Jaminan } \\
\text { Sosial Wajib }\end{array}$ & $4.172 .196,31$ & 4.384.611,62 & $4.597 .265,29$ & $4.697 .025,94$ & 4.867.861,44 \\
\hline Jasa Pendidikan & $7.595 .525,11$ & $8.052 .649,04$ & $8.531 .781,66$ & $\begin{array}{c}9 . .064 .164,8 \\
3\end{array}$ & $9.668 .100,19$ \\
\hline $\begin{array}{c}\text { Jasa Kesehatan dan } \\
\text { Kegiatan Sosial }\end{array}$ & $2.502 .680,04$ & $2.649 .121,77$ & $2.804 .625,21$ & $3.023 .591,50$ & $3.254 .593,89$ \\
\hline Jasa lainnya & $4.836 .400,63$ & $5.077 .815,14$ & $5.224 .596,95$ & $5.495 .449,09$ & $5.821 .770,58$ \\
\hline PDRB Kota Surabaya & $\begin{array}{c}324.215 .166 \\
88\end{array}$ & $\begin{array}{c}343.652 .595 \\
01\end{array}$ & $\begin{array}{c}364.714 .819 \\
48\end{array}$ & $\begin{array}{c}387.303 .942 \\
07\end{array}$ & $\begin{array}{c}410.879 .306 \\
14\end{array}$ \\
\hline
\end{tabular}


Apabila kita melihat dari Tabel 2, kita bisa melihat laju Indeks Implisit PDRB kota Surabaya tahun 2015 adalah dengan angka sebesar 4,92\%, kemudian pada tahun 2016 mengalami penurunan 1,86\%. Untuk tahun selanjutnya, yaitu tahun 2017 terjadi penurunan Indeks Implisit sebesar 39,54\% dan pada tahun 2018 tidak terjadi penurunan Indeks Implisit dimana nilai indeksnya tetap pada 2,92\% kemudian tahun 2019 terjadi penurunan sebesar 46,91\%. Dimana dengan data tersebut kita dapat menarik kesimpulan bahwa mulai dari tahun 2016 Kota Surabaya mengalami penurunan harga setiap tahunnya, dan penurunan harga paling signifikan pada tahun 2019 dengan angka sebesar 46,91\% yang juga menyebabkan peningkatan nilai PDRB kota Surabaya meningkat Rp. 23.575.364,07 dalam nilai jutaan rupiah.

Tabel 2. Tabel Laju Indeks Implisit PDRB Kota Surabaya Menurut Lapangan Usaha, 2015 - 2019 (Dalam Persen \%)

\begin{tabular}{|c|c|c|c|c|c|}
\hline \multirow{2}{*}{ Kategori / Sektor } & \multicolumn{5}{|c|}{ Laju Pertumbuhan (Dalam Persen \%) } \\
\hline & 2015 & 2016 & 2017 & 2018 & 2019 \\
\hline $\begin{array}{l}\text { Pertanian, Kehutanan, } \\
\text { dan Perikanan }\end{array}$ & 6,16 & 3,81 & 5,66 & 4,93 & 2,56 \\
\hline $\begin{array}{l}\text { Pertambangan dan } \\
\text { Penggalian }\end{array}$ & 6,47 & 4,88 & 2,48 & 5,18 & 2,86 \\
\hline Industri Pengolahan & 4 & 3,96 & 3,7 & 3,99 & 2,4 \\
\hline $\begin{array}{c}\text { Pengadaan Listrik dan } \\
\text { Gas }\end{array}$ & 8 & 3,51 & 3,73 & 2,17 & 1,8 \\
\hline $\begin{array}{c}\text { Pengadaan Air, } \\
\text { Pengelolaan Sampah, } \\
\text { Limbah dan Daur Ulang }\end{array}$ & 4,14 & 2,26 & 2,1 & 0,93 & $-1,37$ \\
\hline $\begin{array}{c}\text { Konstruksi } \\
\text { Perdagangan Besar dan }\end{array}$ & 4,29 & 5,73 & 2,86 & 0,39 & $-2,07$ \\
\hline $\begin{array}{l}\text { Eceran; Reparasi Mobil } \\
\text { dan Sepeda Motor }\end{array}$ & 5,2 & 5,42 & 2,46 & 3,58 & 2,04 \\
\hline $\begin{array}{l}\text { Transportasi dan } \\
\text { Pergudangan }\end{array}$ & 5,6 & 5,36 & 3,86 & 2,18 & 0,76 \\
\hline $\begin{array}{l}\text { Penyediaan Akomodasi } \\
\text { dan Makan Minum }\end{array}$ & 5,49 & 5,86 & 2,59 & 2,29 & 1,9 \\
\hline $\begin{array}{l}\text { Informasi dan } \\
\text { Komunikasi }\end{array}$ & 3,47 & 3,14 & 1,61 & 0,01 & 0,83 \\
\hline $\begin{array}{c}\text { Jasa Keuangan dan } \\
\text { Asuransi }\end{array}$ & 4,44 & 3,48 & 3,32 & 4,72 & 1 \\
\hline Real Estate & 8,72 & 2,33 & 3,05 & 4,22 & 2,28 \\
\hline $\begin{array}{l}\text { Jasa Perusahaan } \\
\text { Administrasi }\end{array}$ & 5,18 & 5,57 & 3,82 & 4,71 & 2,97 \\
\hline $\begin{array}{l}\text { Pemerintahan, } \\
\text { Pertahanan dan Jaminan } \\
\text { Sosial Wajib }\end{array}$ & 5,76 & 5,67 & 3,76 & 6,22 & 5,82 \\
\hline Jasa Pendidikan & 3,17 & 2,49 & 2,27 & 1,52 & 1,82 \\
\hline $\begin{array}{c}\text { Jasa Kesehatan dan } \\
\text { Kegiatan Sosial }\end{array}$ & 5,53 & 3,64 & 3,95 & 0,79 & 1,83 \\
\hline Jasa lainnya & 8,15 & 4,37 & 1,84 & 3,28 & 1,34 \\
\hline PDRB Kota Surabaya & 4,92 & 4,83 & 2,92 & 2,92 & 1,55 \\
\hline
\end{tabular}

Berdasarkan dari data distribusi PDRB Kota Surabaya tahun 2015 - 2019 yang dihitung dalam persen (\%) pada Tabel 3, kita bisa melihat bahwa setiap distribusi PDRB kota Surabaya atas dasar harga konstan menurut lapangan usaha jika dijumlahkan mencapai angka 100\% dari tahun 2015 sampai dengan tahun 2019. Dari data tabel diatas kita juga bisa melihat bahwa sektor pertambangan dan 
penggalian menyumbang persentase paling sedikit dalam 5 (lima) tahun terakhir, yaitu hanya $0,01 \%$. Sedangkan untuk sektor yang memiliki kontribusi paling besar dalam peningkatan PDRB kota Surabaya adalah sektor perdagangan besar dan eceran; reparasi mobil dan sepeda motor yang menyumbang persentase diatas $28 \%$ dalam 5 (lima) tahun terakhir.

Untuk diketahui, kota Surabaya adalah sebuah kota yang dijuluki sebagai kota pahlawan. Pertumbuhan penduduk ini berdampak negatif karena bisa meningkatkan tingkat kemiskinan, kekurangan pangan, pemerintah mengalami kesulitan menyajikan sarana kebutuhan masyarakat dan tidak seimbangnya kebutuhan akan lapangan kerja.

Tabel 3. Tabel Distribusi PDRB Kota Surabaya atas Dasar Harga Konstan menurut Lapangan Usaha, 2015-2019 (Dalam Persen \%)

\begin{tabular}{|c|c|c|c|c|c|}
\hline \multirow{2}{*}{ Kategori / Sektor } & \multicolumn{5}{|c|}{ Laju Pertumbuhan (Dalam Persen \%) } \\
\hline & 2015 & 2016 & 2017 & 2018 & 2019 \\
\hline $\begin{array}{c}\text { Pertanian, Kehutanan, dan } \\
\text { Perikanan }\end{array}$ & 0,17 & 0,17 & 0,16 & 0,15 & 0,14 \\
\hline $\begin{array}{l}\text { Pertambangan dan } \\
\text { Penggalian }\end{array}$ & 0,01 & 0,01 & 0,01 & 0,01 & 0,01 \\
\hline Industri Pengolahan & 19,58 & 19,38 & 19,16 & 18,93 & 18,81 \\
\hline Pengadaan Listrik dan Gas & 0,47 & 0,44 & 0,42 & 0,4 & 0,38 \\
\hline Pengadaan Air, Pengelolaan & & & & & \\
\hline $\begin{array}{l}\text { Sampah, Limbah dan Daur } \\
\text { Ulang }\end{array}$ & 0,15 & 0,15 & 0,15 & 0,15 & 0,15 \\
\hline Konstruksi & 9,95 & 9,85 & 9,93 & 9,93 & 9,87 \\
\hline $\begin{array}{l}\text { Perdagangan Besar dan } \\
\text { Eceran; Reparasi Mobil dan } \\
\text { Sepeda Motor }\end{array}$ & 28,4 & 28,36 & 28,32 & 28,37 & 28,31 \\
\hline $\begin{array}{l}\text { Transportasi dan } \\
\text { Pergudangan }\end{array}$ & 4,87 & 4,82 & 4,86 & 4,92 & 4,99 \\
\hline $\begin{array}{c}\text { Penyediaan Akomodasi dan } \\
\text { Makan Minum }\end{array}$ & 14,16 & 14,52 & 14,86 & 15,08 & 15,3 \\
\hline Informasi dan Komunikasi & 6,46 & 6,52 & 6,57 & 6,61 & 6,7 \\
\hline Jasa Keuangan dan Asuransi & 4,92 & 5 & 4,85 & 4,79 & 4,67 \\
\hline Real Estate & 2,68 & 2,66 & 2,63 & 2,62 & 2,62 \\
\hline Jasa Perusahaan & 2,28 & 2,26 & 2,27 & 2,29 & 2,31 \\
\hline $\begin{array}{l}\text { Administrasi Pemerintahan, } \\
\text { Pertahanan dan Jaminan } \\
\text { Sosial Wajib }\end{array}$ & 1,29 & 1,28 & 1,26 & 1,21 & 1,18 \\
\hline Jasa Pendidikan & 2,34 & 2,34 & 2,34 & 2,34 & 2,35 \\
\hline $\begin{array}{c}\text { Jasa Kesehatan dan Kegiatan } \\
\text { Sosial }\end{array}$ & 0,77 & 0,77 & 0,77 & 0,78 & 0,79 \\
\hline Jasa lainnya & 1,49 & 1,48 & 1,43 & 1,42 & 1,42 \\
\hline PDRB Kota Surabaya & 100 & 100 & 100 & 100 & 100 \\
\hline
\end{tabular}

\section{KESIMPULAN}

Berdasarkan data diatas, didapatkan kesimpulan bahwa pertumbuhan ekonomi kota Surabaya sangat bagus dimana nilai PDRB setiap tahunnya bertambah dimana indeks implisit setiap tahun mengalami penurunan serta distribusi PDRB kota Surabaya selalu mencapai angka 100\%. Pihak penulis menyarankan kepada pemerintah daerah kota Surabaya untuk selalu menyiapkan strategi dalam mengatasi berbagai ancamannya yang bisa menyebabkan penurunan ekonomi atau PDRB. Adapun strategi yang bisa terapkan oleh pemerintah kota Surabaya yaitu selalu mengadakan sosialisasi kepada masyarakat terkait cara yang lebih efisien dalam menjalankan usaha, serta melakukan kerja sama dan 
membimbing para pemilik usaha agar usaha mereka bisa berkembang sesuai dengan target yang diharapkan.

\section{DAFTAR PUSTAKA}

Dama, H. Y. (2016). Pengaruh Produk Domestik Regional Bruto (PDRB) Terhadap Tingkat Kemiskinan di Kota Manado (Tahun 2005-2014). Jurnal Berkala Ilmiah Efisiensi, 16(3).

Horota, P., Riani, I. A. P., \& Marbun, R. M. (2017). Peningkatan Pendapatan Asli Daerah dalam rangka Otonomi Daerah melalui potensi pajak dan retribusi daerah di Kabupaten Jayapura. Jurnal Kajian Ekonomi Dan Keuangan Daerah, 2(1).

Mudji, A., \& Taripar, W. (2018). Analisa Produk Domestik Bruto (Pdrb) Kota Malang. PANGRIPTA Jurnal Ilmiah Kajian Perencanaan Pembangunan, 1(1), 35-46.

Perdana, T. A., Budiantoro, R. A., \& Putra, F. I. F. S. (2020). Mengukur kinerja apbd kota surabaya analisis value for money. INOVASI, 16(2), 339-346.

Ratnadila, N. S. (2018). Perencanaan Skenario untuk Pembangunan Desa Tertinggal: Sebuah Telaah Kritis. Jurnal Penyuluhan Perikanan Dan Kelautan, 12(2), 111-128.

Sugiyono, D. (2013). Metode penelitian pendidikan pendekatan kuantitatif, kualitatif dan $R \& D$.

Sutrisno, H. (2015). SENGKETA PASAR KOBLEN SURABAYA (Studi Konflik Rencana Penutupan Pasar Koblen oleh Pemkot Surabaya). UNIVERSITAS AIRLANGGA.

Tineges, R. (2021). Data Sekunder Adalah Jenis Data Penelitian yang Wajib Diketahui. Www.Dqlab.Id. https://www.dqlab.id/data-sekunder-adalah-jenis-data-penelitian-yang-wajib-diketahui

Widyananda, R. F. (2021). 8 Jenis Penelitian Kualitatif dalam Karya Tulis, Menambah Wawasan. Www.Merdeka.Com. https://www.merdeka.com/jatim/8-jenis-penelitian-kualitatif-dalam-karyatulis-menambah-wawasan-kln.html

Yuliani, W. (2018). Metode penelitian deskriptif kualitatif dalam perspektif bimbingan dan konseling. Quanta, 2(2), 83-91. 